\title{
Detection of DNA crosslinks in peripheral lymphocytes isolated from patients treated with platinum derivates using modified comet assay
}

\author{
P. FIKROVA ${ }^{1, *}$, R. STETINA ${ }^{2}$, M. HRNCIARIK ${ }^{3}$, V. REHACEK ${ }^{4}$, P. JOST ${ }^{5}$, M. HRONEK ${ }^{6}$, Z. ZADAK \\ ${ }^{1}$ Department of Biological and Medical Sciences, Faculty of Pharmacy, Charles University, Hradec Králové, Czech Republic; ${ }^{2}$ Department of \\ Toxicology, Faculty of Military Health Sciences, University Defence, Hradec Králové, Czech Republic; ${ }^{3}$ Pulmonary Department, University Hos- \\ pital Hradec Králové, Hradec Králové, Czech Republic; ${ }^{4}$ Transfusion Department, University Hospital Hradec Králové, Hradec Králové, Czech \\ Republic; ${ }^{5}$ Department of Toxicology, Faculty of Military Health Sciences, University Defence, Hradec Králové, Czech Republic; ${ }^{6}$ Department \\ of Biological and Medical Sciences, Faculty of Pharmacy, Charles University, Hradec Králové, Czech Republic; ${ }^{7}$ Department of Research and \\ Development, University Hospital Hradec Králové, Hradec Králové, Czech Republic
}

*Correspondence: petra.fikrova@faf.cuni.cz

Received October 19, 2012 / Accepted December 20, 2012

\begin{abstract}
Platinum-based chemotherapeutic agents induce the formation of crosslinks in DNA, which are accepted as being responsible for the cytotoxicity of these agents. In this study, we used a modification of the alkaline comet assay for detection of the presence of DNA crosslinks in vitro caused by cisplatin, and in peripheral lymphocytes of patients with non-small cell lung carcinoma undergoing chemotherapy with platinum derivatives. The comet technique modified for the detection of DNA crosslinks was calibrated in vitro by treating HeLa cells and human lymphocytes from healthy donors with different concentrations of cisplatin. A cisplatin dose-dependent formation of DNA crosslinks was observed in in vitro measurements using 10-200 $\mu \mathrm{M}$ concentrations of cisplatin. Lymphocytes from cancer patients were also assayed for the formation and repair of DNA crosslinks. Evidence of crosslink formation and repair was observed in peripheral blood lymphocytes of all cancer patients in this study, although some inter-individual differences were observed in the response to chemotherapy and in repair of DNA crosslinks. We propose that monitoring the number of DNA crosslinks in peripheral blood lymphocytes might be a quick and sensitive method for monitoring a patient's sensitivity to this agent. Modification of the method by incubation of analysed cells with styrene oxide before crosslink analysis by comet assay extends the use of the method also to laboratories which have no facilities to use ionizing irradiation for introducing DNA breaks into the cells.
\end{abstract}

Key words: comet assay, DNA crosslinks, cisplatin

Platinum-based chemotherapeutic agents have been used in the treatment of various types of tumor (sarcoma, small cell lung cancer, lymphoma, ovarian cancer and other solid tumors) [1]. Cisplatin was the first platinum agent to be used in the clinical studies in the early 1970s and proved to be very effective in the treatment of several cancer types $[1,2,3]$. Cisplatin is classed as an alkylating agent - DNA binds to it by nucleophilic substitution, and is one of the substances which can cause crosslinking [4]. Cisplatin reacts with DNA by several mechanisms - most common is the reaction with guanine leading to the formation of intrastrand crosslinks (65\% of DNA modifications). It has been shown that platinum-DNA adducts correlate with the disease response. Thus the capacity to repair DNA damage caused by platinum derivatives may reflect cellular sensitivity to this agent $[5,6]$.
DNA damage in single cells can be determined by several methods (e.g. chromosome aberration test or micronucleus test). We performed our measurement using the comet assay test. The comet assay or single-cell gel electrophoresis (SCGE) assay is a rapid, sensitive and relatively simple method for detecting DNA damage at the level of individual cells [7]. This assay is now widely accepted as a standard method for assessing DNA damage in individual cells, and is used in a broad variety of applications including human biomonitoring, genotoxicology, ecological monitoring and as a tool to investigate DNA damage and repair in different cell types in response to a range of DNA-damaging agents [8]. The comet assay would be eminently suitable for use in clinical practice since it is a relatively simple and inexpensive technique, which requires only a small quantity of cells, and results can be obtained 
within a matter of hours [9]. Comet assay is a method specific for investigation of DNA damage, and is recommended for studies on reagents that cause DNA damage.

There have been many studies on patients under treatment for cancer, some of which were focused on the determination of crosslinks. Crosslinks are not readily detected with the standard protocol. In a modified version of the assay a fixed number of random DNA single-strand breaks are induced in cells by irradiation, causing the DNA to unwind in alkali before and during the electrophoresis $[1,5,10,11]$. In another modification of the comet assay for measurement of DNA crosslinks, cells are incubated in the presence of methyl methanesulfonate [12] or $\mathrm{H}_{2} \mathrm{O}_{2}$ [13]. In our study, we decided to use styrene oxide to induce breaks in the DNA. Styrene oxide is a major metabolite of styrene which forms adducts with DNA, predominantly at the N7 position of guanine. After incubation with cells it creates breaks in DNA [14]. There is a relatively quick repair of the resulting damage, about half of the breaks being repaired within 2-4 hours, and the repair being almost complete after 12 hours [15]. The ability of styrene oxide to create breaks in the DNA of mammalian cells has been confirmed in in vitro experiments and also in vivo $[16,17,18]$. Experimental studies have also shown that the dependence of the number of DNA breaks on the concentration of styrene oxide is almost linear [18].

\section{Materials and methods}

Chemicals and reagents. All chemicals were purchased from Sigma Aldrich.

Cell culture. HeLa cells were obtained from Prof. Andrew Collins (University of Oslo, Norway). Cells were cultivated in the medium DMEM supplemented with $1 \%$ of fetal bovine serum, antibiotics and an antimycotic mixture (all ingredients from PAA laboratories, Austria). Cells were passaged twice weekly by trypsinisation in the ratio 1:10.

Cisplatin treatment of cells. Cells were separated into eppendorf tubes at a density of 1 million cells per ml. and incubated with different concentrations of cisplatin for $1 \mathrm{~h}$ at $37^{\circ} \mathrm{C}$ for formation of the crosslinks. Freshly prepared solutions of cisplatin in DMSO were used to cell treatment.

Patients and ethical approval. Blood samples were obtained from five patients with non-small cell lung carcinoma stage 4 . The patients aged were between 54 and 67 . They were programmed for chemotherapy with the following protocol. Blood samples were collected from each patient during the $1^{\text {st }}$ and $3^{\text {rd }}$ cycles of chemotherapy: 1 day before starting the cycle, immediately after administration of the chemotherapy, and 1 and 7 days after completion of the chemotherapy cycle. The last control measurement was performed 3 weeks after the final ( $4^{\text {th }}$ cycle) completed course of chemotherapy. The study was conducted according to the guidelines laid down in the Declaration of Helsinki and all procedures involving human subjects were approved by the Ethics Committee of Charles University Medical Faculty in Hradec Kralove. Written informed consent was obtained from all subjects.
Lymphocyte preparation. Peripheral blood lymphocytes were obtained from heparinized blood and separated using LSM (PAA laboratories, Austria) according to the method of Boyum 1964 [19]. Peripheral blood lymphocytes were washed and re-suspended with PBS buffer and adjusted to 1 million cells $/ \mathrm{ml}$.

In the case of in vitro measurement of the induction of crosslinks, the isolated lymphocytes were re-suspended in RPMI medium (PAA laboratories, Austria) supplemented with $10 \%$ of fetal bovine serum and incubated for $1 \mathrm{~h}$ in the presence of various concentrations of cisplatin. The degree of crosslinking was estimated by comet assay (see below).

Comet assay. The comet assay modification described previously (Collins et al. 1997 [20]) was used. Briefly, $35 \mu \mathrm{L}$ of cell suspension (»35000 cells) was mixed with $85 \mu \mathrm{L}$ low meltingpoint agarose, spread onto an $85 \mu \mathrm{L}$ high melting-point normal agarose pre-coated microscope slide and allowed to solidify at $4^{\circ} \mathrm{C}$. Cells were lysed for $1 \mathrm{~h}$ in high salt and detergent. They were then exposed to alkali for $40 \mathrm{~min}$ to allow DNA unwinding and cleavage of alkali-labile sites. Electrophoresis was applied for $30 \mathrm{~min}$ at $4^{\circ} \mathrm{C}$. The slides were then neutralized, stained with ethidium bromide and analyzed by fluorescence microscopy. Fifty cells were scored according to percentage Tail DNA by Lucia G analysing software (Laboratory imaging, Prague).

Measurement of crosslinks. For the measurement of crosslinks we incubated lymphocytes with $200 \mu \mathrm{M}$ styrene oxide to induce DNA breaks, which leads in untreated cells to the formation of comets containing about $80-90 \%$ of DNA in the tail. When crosslinks are present in the DNA the alkali-induced unwinding is blocked (due to covalent binding to DNA) and the percentage of DNA in the tail is reduced accordingly.

Statistical analysis. Statistical significance in the differences between measurements was assessed by t-test and/or ANOVA test using GraphPad Prism 5.03 software (GraphPad Software, Inc., San Diego, California, U.S.A.).

\section{Results}

In vitro studies. Formation of DNA crosslinks in response to cisplatin was investigated in HeLa cells and in human peripheral lymphocytes by use of the modified alkaline comet assay that enables detection of these lesions.

HeLa cells and lymphocytes were incubated with varying concentrations of cisplatin $(0 \mu \mathrm{M} ; 12,5 \mu \mathrm{M} ; 25 \mu \mathrm{M} ; 50 \mu \mathrm{M} ; 100$ $\mu \mathrm{M} ; 200 \mu \mathrm{M})$. The cells were then incubated for 1 hour in the presence of $200 \mu \mathrm{M}$ styrene oxide to induce DNA breaks, before being examined by comet assay. Cells not influenced by the cisplatin display comets containing about $80-90 \%$ of DNA in the tail ( $65 \%$ in the case of HeLa cells). When crosslinks caused by cisplatin are present in the DNA the alkaline unwinding is blocked, and the percentage of DNA in the tail is reduced in a dose-dependent manner in both the HeLa cells and the human lymphocytes (Fig.1). The highest incidence of crosslinks was observed with the highest concentrations of cisplatin $-200 \mu \mathrm{M}$. 


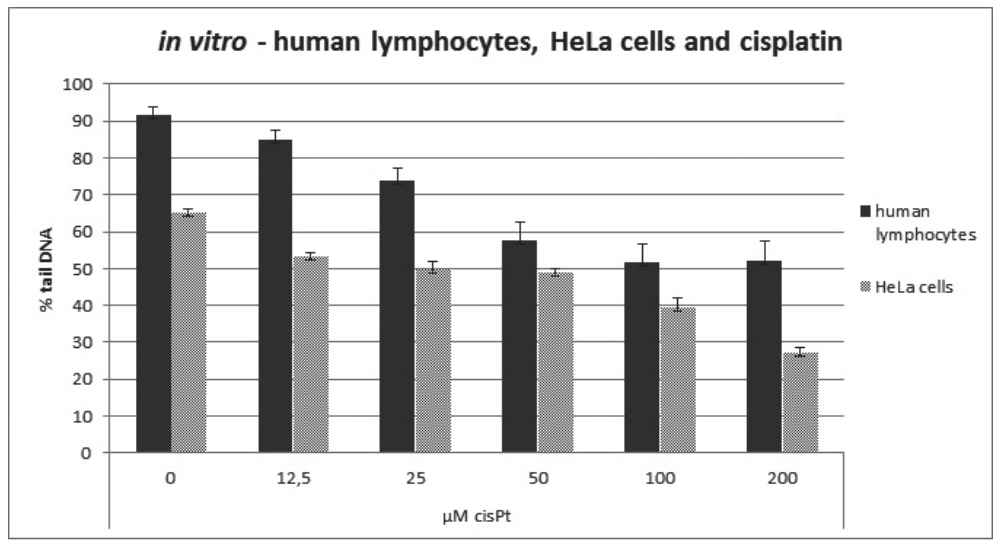

Figure 1. Measurement of DNA crosslinks caused by cisplatin in vitro in HeLa cells and in human lymphocytes as a percentage of DNA in the tail of a comet in the alkaline comet assay. The number of cells scored in each measured concentration was 50. In both cases the percentage of Tail DNA decreases with increasing concentrations of cisplatin. The highest incidence of crosslinks was observed with the highest concentrations of cisplatin. In HeLa cells $P$ value in ANOVA test was $<0.0001$. In human lymphocytes $P$ value in ANOVA test was 0,04 .

In vivo studies. We investigated the level of DNA crosslinks in peripheral blood lymphocytes in five patients with nonsmall cell lung cancer during treatment with platinum derivatives. Peripheral lymphocytes were isolated from whole blood and examined by comet assay protocol modified with styrene oxide. Data were collected 1 day before the start of chemotherapy, during the $1^{\text {st }}$ and $3^{\text {rd }}$ cycle of chemotherapy, immediately after the end of chemotherapy, and then 1 and 7 days after completion of chemotherapy. The last control measurement was performed 3 weeks after the final ( $4^{\text {th }}$ cycle $)$ completed course of the chemotherapy.

In this study, a significant reduction in percentage Tail DNA was found in all patients during the first and third cycle of the chemotherapy, indicating the presence of crosslinks.
The value of Tail DNA increased again after one week although it did not reach the baseline values. The response in patients showed a similar trend, although there appears to be high inter-individual variability. Fig.2 shows the course of the chemotherapy in one of the patients as a record of percentage Tail DNA caused by cisplatin crosslinking in every measured chemotherapy cycles. The complete results for all patients as a percentage Tail DNA are displayed in Table 1. For better reproducibility of results, the decrease in percentage Tail DNA caused by crosslinking were calculated for measurements immediately after chemotherapy, 1 day after chemotherapy and 7 days after chemotherapy, using the formula published by Wynne et al. 2007 [21]. Results are displayed in Table 2.

Table 1. \% Tail DNA in each measurement in patients

\begin{tabular}{|c|c|c|c|c|c|c|c|c|c|c|c|}
\hline \multirow[t]{2}{*}{ patient } & \multirow[t]{2}{*}{ age } & \multirow[t]{2}{*}{ gender } & \multicolumn{4}{|c|}{ 1. cyclus \% Tail DNA } & \multicolumn{4}{|c|}{ 3.cyclus \%Tail DNA } & \multirow[t]{2}{*}{ the end of therapy \% Tail DNA } \\
\hline & & & -1 & $\mathbf{0}$ & 1 & 7 & -1 & $\mathbf{0}$ & 1 & 7 & \\
\hline 1 & 54 & $\mathbf{M}$ & 84,63 & 51,3 & 63,76 & 63,71 & 99,8 & 73,59 & 93,14 & 98,15 & 82,65 \\
\hline 2 & 65 & $\mathbf{M}$ & 83,85 & 80,45 & 76,74 & 76,95 & 90,24 & 37 & 73,54 & 66,21 & 83,77 \\
\hline 3 & 63 & $\mathbf{M}$ & 77,33 & 40,68 & 53,73 & 51,11 & 90,49 & 67,51 & 67,84 & 80,55 & 75,29 \\
\hline 4 & 52 & $\mathbf{M}$ & 84,56 & 56,51 & 48,34 & 62,97 & 91,96 & 50,9 & 62,14 & 68,91 & 70,69 \\
\hline 5 & 67 & $\mathbf{F}$ & 78,53 & 72,42 & 55,21 & 77,72 & 83,27 & 77,56 & 63,46 & 66,75 & 73,45 \\
\hline
\end{tabular}

Measurement of DNA crosslinks in peripheral lymphocytes of patients with non-small cell lung carcinoma undergoing platinum derivative-based chemotherapy as a percentage of DNA in the tail of a comet in the alkaline comet assay. In each cycle: -1 stands for measurement before starting chemotherapy, 0 stands for measurement immediately after the administration of chemotherapy, 1 and 7 stands for measurement 1 and 7 days after administration of chemotherapy. Measurement at the end of therapy was performed 3 weeks after the last ( $4^{\text {th }}$ cycle) course of chemotherapy. The number of cells scored in each measurement was 50. A significant reduction of tail DNA after the chemotherapy indicated the presence of crosslinks in all patients was found in $1^{\text {st }}$ and $3^{\text {rd }} \mathrm{cycle}$ (In measurement of patient $1, \mathrm{P}$ value in 1st and 3rd cycle was $<0.0001$, in measurement of patient 2 , P value in 1 st cycle was 0,0456 and in 3 rd cycle was $<0.0001$, in measurement of patient 3 , P value in 1 st and 3rd cycle was $<0.0001$, in patient 4 , P value in 1 st and 3rd cycle was $<0.0001$ and also in patient 5 (Fig. 5), P value in 1 st and 3 rd cycle was $<0.0001$. Also residual crosslinks which persist at the end of chemotherapy were found in the DNA of peripheral lymphocytes in all patients, but only in the case of three patients the difference between measurement before and after the whole therapy was significant (in measurement of patient 1, P value in Mann-Whitney test was nonsignificant, in measurement of patient 2, P value in Mann-Whitney test was $<0.0001$, in measurement of patient 3, P value in Mann-Whitney test was nonsignificant, in measurement of patient 4, $\mathrm{P}$ value in Mann-Whitney test was 0,0098 and in measurement of patient 5, P value in Mann-Whitney test was $<0.0001$. 


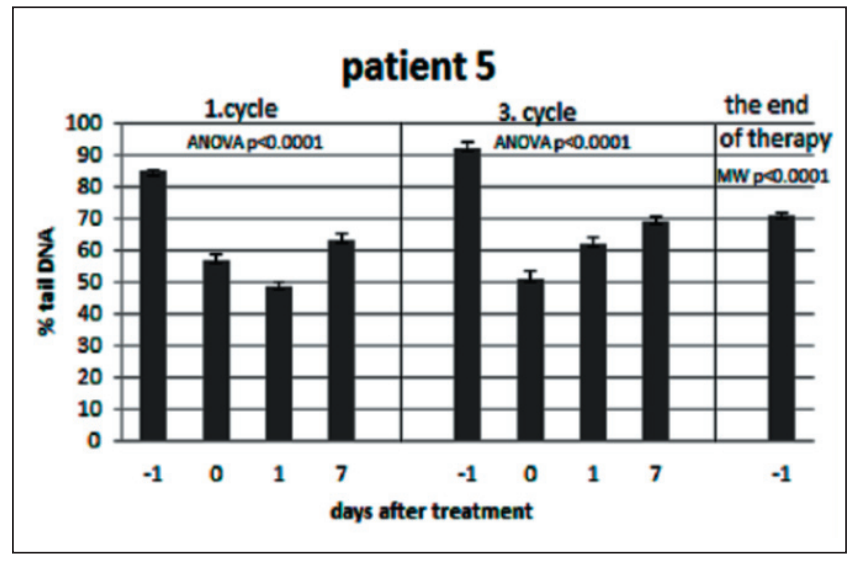

Figure 2. Measurement of DNA crosslinks in peripheral lymphocytes of patients with non-small cell lung carcinoma undergoing platinum derivative-based chemotherapy as a percentage of DNA in the tail of a comet in the alkaline comet assay. In each cycle: $\mathbf{- 1}$ stands for measurement before starting chemotherapy, 0 stands for measurement immediately after the administration of chemotherapy, 1 and 7 stand for measurement 1 and 7 days after administration of chemotherapy. Measurement at the end of therapy was performed 3 weeks after the last $\left(4^{\text {th }}\right.$ cycle) course of chemotherapy. The number of cells scored in each measurement was 50. A significant reduction of Tail DNA immediately after the chemotherapy indicated the presence of crosslinks ( $P$ value in ANOVA test measured in $1^{\text {st }}$ and $3^{\text {rd }}$ cycle of chemotherapy was $\left.<\mathbf{0 . 0 0 0 1}\right)$. The value of Tail DNA increased again after one week although it did not reach the baseline values. Some residual crosslinks were found at the end of chemotherapy ( $P$ value in Mann-Whitney test was $<0.0001)$.

\section{Discussion}

Platinum-derived chemotherapeutic agents have been used in the treatment of various tumours. They induce the formation of DNA crosslinks, which are thought to be responsible for its cytotoxic effect [1]. The aim of this study was to assess the possibility of using modified comet assay to detect the presence of crosslinks or even to estimate the number of crosslinks in patients' DNA introduced by platinum chemotherapy.

A modification of the comet assay test - incubation of $\mathrm{HeLa}$ cells and human lymphocytes with styrene oxide - was used for in vitro detection of crosslinks. Our results confirmed that the in vitro damage of DNA caused by the cisplatin depends on the concentration of cisplatin. In cells treated with styrene oxide a decrease in percentage Tail DNA values suggests the formation of crosslinks. Creation of crosslinks was observed at a concentration $12.5 \mu \mathrm{M}$ of cisplatin in both HeLa cells and human lymphocytes, and the amount of crosslinking increased with increasing concentrations of cisplatin. The dependence on concentration of cisplatin in the creation of crosslinks in DNA in different cell types has been described previously. Authors of these studies confirm that there is positive linear correlation of cisplatin concentration with the number of established crosslinks in DNA [22, 23].

The method was also used for in vivo detection of crosslinks in patients treated with platinum derivatives. The degree of crosslinking was measured during whole course of the chemotherapy, with sampling being carried out in each measured chemotherapy cycle before chemotherapy, immediately after chemotherapy, 1 day after chemotherapy and 7 days after chemotherapy. We found a significant reduction in percentage Tail DNA in all patients during the first and third cycle of the chemotherapy, suggesting the creation of crosslinks, which was comparable to the in vitro effect of cisplatin concentrations of 12.5-100 $\mu \mathrm{M}$. The value of Tail DNA increased again after one week although it did not reach the baseline values. However this seems that crosslinks are partially repaired in this interval. These results are consistent with the results of Peng et al 1997 [24], who studied the formation of cisplatin adducts in leucocytes of children in relation to pharmacokinetics. In this study it was demonstrated that the levels of cisplatin adducts increased during the $24 \mathrm{~h}$ infusion and then declined over the next $24 \mathrm{~h}$ (24). The response in all patients showed a similar trend, although inter-individual differences were found. During the first cycle of chemotherapy we found only a small

Table 2. DNA crosslink formation in patients

\begin{tabular}{|c|c|c|c|c|c|c|c|c|c|}
\hline \multirow[b]{2}{*}{ patient } & \multirow[b]{2}{*}{ age } & \multirow[b]{2}{*}{ gender } & \multicolumn{3}{|c|}{ 1. cyclus $\%$ decrease of Tail DNA } & \multicolumn{3}{|c|}{ 3.cyclus $\%$ decrease of Tail DNA } & \multirow{2}{*}{$\begin{array}{c}\% \text { decrease Tail DNA } \\
\text { before : after the whole therapy }\end{array}$} \\
\hline & & & post chemo & 1 day & 7 days & post chemo & 1 day & 7 days & \\
\hline 1 & 54 & $\mathrm{M}$ & 41,54 & 26,03 & 26,10 & 27,29 & 6,93 & 1,72 & 2,47 \\
\hline 2 & 65 & M & 3,82 & 8,00 & 7,76 & 65,51 & 20,55 & 29,57 & 11,33 \\
\hline 3 & 63 & M & 49,30 & 31,80 & 35,30 & 31,12 & 26,56 & 11,66 & 2,75 \\
\hline 4 & 52 & M & 2,73 & 12,78 & 2,12 & 31,16 & 56,35 & 10,30 & 15,97 \\
\hline 5 & 67 & $\mathrm{~F}$ & 38,89 & 50,22 & 29,94 & 45,76 & 33,23 & 25,69 & 19,23 \\
\hline
\end{tabular}

Measurement of DNA crosslinks formation in patients with non-small cell lung carcinoma undergoing platinum derivative-based chemotherapy as a percentage of DNA in the tail of a comet in the alkaline comet assay calculated by the formula published by Wynne et al. (21). In each cycle: post chemo stands for measurement immediately after the administration of chemotherapy, 1 day and 7 days stands for measurements 1 and 7 days after administration of chemotherapy. Measurement at the end of therapy was performed 3 weeks after the last (4th cycle) course of chemotherapy. The number of cells scored in each measurement was 50. A reduction of percenatge Tail DNA showing the presence of crosslinks was found in all patients. The response in all patients showed a similar trend, however, some inter-individual differences were found. Residual crosslinks which persist at the end of chemotherapy were found in the DNA of peripheral lymphocytes in all patients. 
reduction in Tail DNA in two patients, and we suppose that the lower number of crosslinks may be related to the activity of DNA repair mechanism. This will be subject to further study. Increased repair of platinum-induced DNA damage is known to be one of the main mechanisms involved in resistance to these agents [25].

Inter-individual differences between patients in the response to the chemotherapy may yield valuable information about patient status with respect to the level of DNA damage and DNA repair capacity, prior to application of another cycle of chemotherapy. In a study by Bosken et al [26] it was demonstrated that increased activity of the repair capacity (NER), measured in lymphocytes of patients with non-small cell lung cancer may be associated with lower survival [26]. On the other hand, some variability between individual patients has been confirmed in other studies [1]. Also, residual crosslinks which persist at the end of chemotherapy were found in the DNA of peripheral lymphocytes in all patients. This may bear some relation to the fact that in some studies performed on patients after chemotherapy it was found that DNA damage increases during treatment and remains elevated even at the end of treatment [27].

Previous studies have found a good correlation between platinum DNA adducts in the blood and patient therapy outcome in tumours $[28,29]$. We might propose that monitoring of DNA crosslink numbers in peripheral blood lymphocytes might be beneficial in assessing the sensitivity of the patient to this agent. Although DNA damage detected in peripheral blood lymphocytes can scarcely be equated to DNA damage in the solid tumour tissue, the relative quantity of crosslinks during the chemotherapy may be monitored as a valuable marker of the effect of the platinum drug on the patient's immune-competent cells and to his health status. This may help to predict the efficacy of the chemotherapy and to tailor the ongoing treatment.

Acknowledgements: This work was supported by MH CZ - DRO (FNHK) and Faculty of Pharmacy [project number SVV/2012/265 003]

\section{References}

[1] ALMEIDA GM, DUARTE TL, STEWARD WP, JONES GD: Detection of oxaliplatin-induced DNA crosslinks in vitro and in cancer patients using the alkaline comet assay. DNA Repair 2005; 5, 219-225. http://dx.doi.org/10.1016/j.dnarep.2005.09.010

[2] ROSENBERG B: Fundamental studies with cisplatin. Cancer 1985; 55, 2303-2316. http://dx.doi.org/10.1002/1097-0142(1 9850515)55:10<2303::AID-CNCR2820551002>3.0.CO;2-L

[3] LEBWOHL D, CANETTA R: Clinical development of platinum complexes in cancer therapy: an historical perspective and an update. Eur J Cancer. 1998; 34, 1522-1534. http:// dx.doi.org/10.1016/S0959-8049(98)00224-X

[4] DRONKERT ML, KANNAR R: Repair of DNA interstrand cross-links. Mutation Research 2001; 486, 217-247. http:// dx.doi.org/10.1016/S0921-8777(01)00092-1
[5] UNGER FT, KLASEN HA, TCHARTCHIAN G, DE WILDE RL, WITTE I: DNA damage induced by cis- and carboplatin as indicator for in vitro sensitivity of ovarian carcinoma cells. BMC Cancer 2009; 9, 359. http://dx.doi.org/10.1186/14712407-9-359

[6] RABIK CA, DOLAN ME: Molecular mechanisms of resistance and toxicity associated with platinating agents. Cancer Treatment Rev. 2007; 33, 9-23. http://dx.doi.org/10.1016/ j.ctrv.2006.09.006

[7] SINGH NP, MCCOY MT, TICE RR, SCHNEIDER EL: A simple technique for the quantitation of low levels of DNA damage in individual cells. Exp Cell Res, 1988; 175, 184-191. http://dx.doi.org/10.1016/0014-4827(88)90265-0

[8] COLLINS AR: The comet assay for DNA damage and repair: principles, applications, and limitations. Mol. Biotechnol. 2004; 26, 249-261. http://dx.doi.org/10.1385/ MB:26:3:249

[9] MCKENNA DJ, MCKEOWN SR, MCKELVEY-MARTIN VJ: Potential use of the comet assay in the clinical management of cancer. Mutagenesis 2008; 23, 183-190. http://dx.doi. org/10.1093/mutage/gem054

[10] HARTLEY JM, SPANSWICK VJ, GANDER M, GIACOMINI G, WHELAN J et al.: Measurement of DNA cross-linking in patients on ifosfamide therapy using the single cell gel electrophoresis (comet) assay. Clin. Cancer Res. 1999; 5, 507-512.

[11] OLIVE PL, BANATH JP: Sizing highly fragmented DNA in individual apoptotic cells using the comet assay and a DNA crosslinking agent. Exp. Cell Res. 1995; 221, 19-26. http:// dx.doi.org/10.1006/excr.1995.1348

[12] PFUHLER S, WOLF U: Detection of DNA-crosslinking agents with alkaline comet assay. Environmental and Molecular Mutagenesis 1996; 27, 196-201. http://dx.doi.org/10.1002/ (SICI) 1098-2280(1996)27:3<196::AID-EM4>3.0.CO;2-D

[13] ZHANG Z, HENG Z, HE F, PANG X: Detection of DNA crosslinks with comet assay. Wei Sheng Yan Jiu, 2001; 30, 146-148.

[14] BASTLOVA T, VODICKA P, PETERKOVÁ K, HEMMINKI K, LAMBERT B: Styrene oxide-induced HPRT mutations, DNA adducts and DNA strand breaks in cultured human lymphocytes. Carcinogenesis 1995; 16, 2357-2362. http://dx.doi. org/10.1093/carcin/16.10.2357

[15] KOHLEROVA R, STETINA R: The repair of DNA damage induced in human peripheral lymphocytes with styrene oxide. Acta Medica 2003; 46, 95-100.

[16] DYPBUKT JM, COSTA LG, MANZO L, ORRENIUS S, NICORETA P: Cytotoxic and genotoxic effects of styrene-7,8oxide in neuroadrenergic Pc 12 cells. Carcinogenesis 1992; 13, 417-424. http://dx.doi.org/10.1093/carcin/13.3.417

[17] WALLES SAS, ORSEN I: Single-strand breaks in DNA of various organs of mice induced by styrene and styrene oxide. Cancer Letter 1983; 21, 9-15. http://dx.doi.org/10.1016/03043835(83)90076-9

[18] VODICKA P, STETINA R, KUMAR R, PLNA K, HEMMINKU $\mathrm{K}$ : 7-Alkylguanine adducts of styrene oxide determined by 32P-postlabelling in DNA and human embryonal lung fibroblasts (HEL). Carcinogenesis 1996; 17, 801-808. http://dx.doi. org/10.1093/carcin/17.4.801 
[19] BOYUM A: Separation of white blood cells. Nature 1964; 204, 793-794. http://dx.doi.org/10.1038/204793a0

[20] COLLINS AR, DOBSON VL, DUSINKSA M, KENNEDY G, STETINA R: The comet assay: what can it really tell us? Mutation Research 1997; 375, 183-193. http://dx.doi. org/10.1016/S0027-5107(97)00013-4

[21] WYNNE P, NEWTON C, LEDERMANN JA, OLAITAN A, MOULD TA et al.: Enhanced repair of DNA interstrand crosslinking in ovarian cancer cells from patients following treatment with platinum-based chemotherapy. British Journal of Cancer 2007; 97, 927-933.

[22] ROBERTS JJ, FRIEDLOS F: Quantitative aspects of the formation and loss of DNA interstrand crosslinks in Chinese hamster cells following treatment with cis-diamminedichloroplatinu $\mathrm{m}$ (II) (cisplatin). I. Proportion of DNA-platinum reactions involved in DNA crosslinking. Biochemica et Biophysica Acta 1981; 655, 146-151. http://dx.doi.org/10.1016/00052787(81)90004-6

[23] PASCOE JM, ROBERTS JJ: Interactions between mammalian cell DNA and inorganic platinum compounds. I. DNA interstrand cross-linking and cytotoxic properties of platinum(II) compounds. Biochemical Pharmacology 1974; 23, 1345-1357. http://dx.doi.org/10.1016/0006-2952(74)90354-2

[24] PENG B, TILBY MJ, ENGLISH MW, PRICE L, PEARSON $\mathrm{AD}$ et al.: Platinum-DNA adduct formation in leucocytes of children in relation to pharmacokinetics after cisplatin and carboplatin therapy. Br J Cancer. 1997; 76, 1466-1473. http://dx.doi.org/10.1038/bjc.1997.579

[25] KARTALOU M, ESSIGMANN JM: Mechanisms of resistance to cisplatin. Mutat. Res. 2001; 478, 23-43. http://dx.doi. org/10.1016/S0027-5107(01)00141-5

[26] BOSKEN CH, WEI Q, AMOS CI, SPITZ MR: An analysis of DNA repair as a determinant of survival in patients with nonsmall-cell lung cancer. J Natl Cancer Inst. 2002; 94, 1091-1099. http://dx.doi.org/10.1093/jnci/94.14.1091

[27] SANCHEZ-SUAREZ P, OSTROSKY-WEGMAN P, GALLEGOS-HERNANDEZ P, PENARROJA-FLORES R, TOLEDO-GARCIA J et al.: DNA damage in peripheral blood lymphocytes in patients during combined chemotherapy for breast cancer. Mutat Res. 2008; 640, 8-15. http://dx.doi. org/10.1016/j.mrfmmm.2007.11.008

[28] REED E, YUSPA SH, ZWELLING LA, OZOLS RF, POIRIER MC: Quantitation of cis-diamminedichloroplatinum II (cisplatin)-DNA-intrastrand adducts in testicular and ovarian cancer patients receiving cisplatin chemotherapy. J. Clin. Invest. 1986; 77, 545-550. http://dx.doi.org/10.1172/ LCI112335

[29] PARKER RJ, GILL I, TARONE R, VIONNET JA, GRUNBERG S et al.: Platinum-DNA damage in leukocyte DNA of patients receiving carboplatin and cisplatin chemotherapy, measured by atomic absorption spectrometry. Carcinogenesis 1991; 12, 1253-1258. http://dx.doi.org/10.1093/carcin/12.7.1253 